\title{
Primjena spektrometrijskih metoda u analizi metalurških uzoraka
}

DOI: $10.15255 /$ KUI.2015.036

KUI-23/2016

Izvorni znanstveni rad

Prispjelo 29. lipnja 2015.

Prihvaćeno 2. rujna 2015.

\section{A. Štrkalj*i Z. Glavaš}

Sveučilište u Zagrebu Metalurški fakultet, Aleja narodnih heroja 3, 44103 Sisak, Hrvatska

\section{|| Sažetak}

Instrumentalne metode analize nezamjenjive su u znanstvenim istraživanjima, a sve više i u praksi gdje se zahtijeva što brže dobivanje rezultata, kao i što veća točnost. U metalurškoj praksi već se dulji niz godina primjenjuju spektrometrijjke metode analize i to najčešće optička emisijska spektrometrija s izravnim očitanjem. Međutim koncentracija pojedinih legirnih elemenata u suvremenim metalnim materijalima vrlo je niska, često niža od granice detekcije optičkih emisijskih spektrometara s izravnim očitanjem.

U ovom radu određivana je koncentracija bora u nodularnom lijevu primjenom optičke emisijske spektrometrije s izravnim očitanjem (OES), optičke emisijske spektrometrije s induktivno spregnutom plazmom (ICP-OES) te atomske apsorpcijske spektrometrije s grafitnom tehnikom (AAS-GF). Dobiveni rezultati pokazali su da se optička emisijska spektrometrija s izravnim očitanjem i optička emisijska spektrometrija s induktivno spregnutom plazmom mogu primijeniti za određivanje bora u ispitivanim uzorcima (tablica 1). Ako se zahtijeva vrlo točna analiza, a posebno ako se radi o vrlo niskim koncentracijama, optička emisijska spektrometrija s induktivno spregnutom plazmom pogodnija je metoda, uz uvjet da su uzorci pravilno pripremljeni. Atomska apsorpcijska spektrometrija s grafitnom tehnikom nije pogodna za određivanje bora u uzorcima ovog tipa. Tijekom provođenja analize dodatna pažnja usmjerena je na eliminaciju negativnog utjecaja grafitne kivete na rezultat analize.

Osim toga, u radu je praćen utjecaj načina otapanja uzoraka na rezultate analize bora spomenutim metodama. Rezultati su pokazali da pažljiva priprema uzoraka u zatvorenom sustavu pridonosi točnijem rezultatu analize.

\section{\| Ključne riječi}

Atomska apsorpcijska spektrometrija s grafitnom tehnikom (AAS-GF), optička emisijska spektrometrija s induktivno spregnutom plazmom (ICP-OES), optička emisijska spektrometrija s izravnim očitanjem (OES), bor, metalurški uzorci

\section{Uvod}

Izbor metode i instrumenata za određivanje kemijskog sastava kao i koncentracije pojedinih elemenata ovisi o nizu zahtjeva koji se postavljaju u istraživanju, ali i proizvodnji i kontroli gotovih proizvoda. Nove tehnologije proizvodnje postavljaju sve strože zahtjeve. Unazad nekoliko desetaka godina bilo je dovoljno odrediti nekoliko osnovnih parametara koji ukazuju na neka fizikalno-kemijska svojstava ispitivanog materijala. U suvremenoj tehnologiji nužno je određivanje većeg broja parametara, često i provjera/potvrđivanje rezultata na sličnim instrumentima kao i brzina i točnost analize. Vrlo je teško pronaći metodu i instrument koji će zadovoljiti sve tražene kriterije. ${ }^{1}$

Određivanje kemijskog sastava metalurških uzoraka ponekad zna biti vrlo složeno jer se ovisno o metodi određivanja zahtijeva prethodna priprema uzoraka. ${ }^{2}$ Ta priprema u pojedinim metodama uključuje raščinjavanje metalurških uzoraka (npr. čelika, lijevova na osnovi željeza ili obojenih metala, troske itd.), odnosno prevođenje u vodenu otopinu, što može biti vrlo složen proces. Budući da metalurški uzorci mogu sadržavati karbide koji se iznimno teško raščinjavaju, često treba primijeniti visoke temperature, odgo-

\footnotetext{
*Autor za dopisivanje: Izv. prof. dr. sc. Anita Štrkalj e-pošta: strkalj@simet.hr
}

varajući tlak i reagense. Pri tome veoma važnu ulogu ima i iskustvo analitičara.

Radi proizvodnje inovativnih materijala poboljšanih svojstava sve se više upotrebljava dodatak legirnih elemenata u vrlo niskim koncentracijama. Pri procesu legiranja, legirni elementi često se ne usvajaju u potpunosti, te je nužno određivanje njihova udjela nakon legiranja. Budući da se često radi o vrlo niskim koncentracijama (ponekad i $<0,001 \mathrm{~kg} \mathrm{~m}^{-3}$ ), nužno je pronaći metodu koja će imati visoku osjetljivost za određivanje većine metala u različitim matricama. Upravo se iz navedenih razloga u metalurškoj praksi izvjesna prednost daje spektrometrijskim metodama određivanja. Te su metode u praksi zastupljene s udjelom od $80 \%$ u odnosu na druge metode ispitivanja kemijskog sastava. $^{3}$

Nodularni lijev je vrsta željeznog lijeva koji danas ima sve širu primjenu za gradnju raznih komponenti zbog povoljnih svojstava. Dodatak legirnih elemenata, često u vrlo niskim koncentracijama, može znatno utjecati na njegovu mikrostrukturu, a time i svojstva. Poznato je da npr. bor u vrlo malim udjelima (reda veličine kilograma po kubnom metru) snažno pospješuje stvaranje feritne metalne osnove, čime se u konačnici povećava duktilnost nodularnog lijeva. ${ }^{4}$ Ta spoznaja primijenjena je u razvoju nove vrste nodularnog lijeva, poznatog pod nazivom SiboDur ${ }^{\circledR}$ koji 
ima specifičnu i povoljnu kombinaciju visoke čvrstoće i duktilnosti, odnosno deformabilnosti. ${ }^{5}$ Danas se intenzivno upotrebljava u automobilskoj industriji za komponente od kojih se zahtijeva visoka sigurnost, a izložene su visokim naprezanjima, kao što su nosači kotača, razne komponente ovjesa, nosači motora, koljenaste osovine itd.

U ovom radu određivana je koncentracija bora u nodularnom lijevu s pomoću tri spektrometrijske metode: atomskom apsorpcijskom spektrometrijom s grafitnom tehnikom (AAS-GF), optičkom emisijskom spektrometrijom s induktivno spregnutom plazmom (ICP-OES) i optičkom emisijskom spektrometrijom s izravnim očitanjem (OES).

\section{Eksperimentalni dio}

Eksperimentalni dio rada obuhvatio je analizu devet uzoraka nodularnog lijeva. Prilikom proizvodnje u talinu su dodavane različite količine legure koja sadrži 162,3 $\mathrm{kg} \mathrm{m}^{-3}$ bora da bi se u nodularnom lijevu postigla koncentracija bora od 0,005 do 0,075 $\mathrm{kg} \mathrm{m}^{-3}$.

Uzorci su uzimani nakon legiranja i u njima su određivane koncentracije bora atomskom apsorpcijskom spektrometrijom s grafitnom tehnikom (Analytik Jena, ZEEnit 650), optičkom emisijskom spektrometrijom s induktivno spregnutom plazmom (Perkin Elmer Optima 2100 DV) i optičkom emisijskom spektrometrijom s izravnim očitanjem (OES) (ARL 3460). Za određivanje bora optičkom emisijskom spektrometrijom s izravnim očitanjem (OES) upotrijebljeni su uzorci u obliku valjčića promjera $50 \mathrm{~mm}$ i visine $5 \mathrm{~mm}$ koji su odliveni tijekom proizvodnje nodularnog lijeva. U takvom obliku upotrijebljeni su za ispitivanja (bez prethodne pripreme).

Budući da su atomska apsorpcijska spektrometrija s grafitnom tehnikom i optička emisijska spektrometrija s in- duktivno spregnutom plazmom metode koje zahtijevaju raščinjavanje uzoraka, uzorci su prethodno prevedeni u vodene otopine.

Prije prevođenja uzorka u vodenu otopinu provedeno je usitnjavanje uzoraka. Prevođenje u vodene otopine provedeno je na dva načina. U prvom slučaju usitnjeni uzorci (1 g) su otapani u kvarcnoj tikvici od $100 \mathrm{ml}$ dodatkom $10 \mathrm{ml}$ klorovodične, $5 \mathrm{ml}$ dušične, $10 \mathrm{ml}$ fosforne i $5 \mathrm{ml}$ sumporne kiseline. Nakon toga je provedeno uparavanje sve do nastanka para $\mathrm{SO}_{3}$. Po završetku uparavanja dodano je još $5 \mathrm{ml}$ klorovodične kiseline. Ovako pripremljeni uzorci razrijeđeni su ultračistom vodom do $100 \mathrm{ml}$. U drugom slučaju upotrijebljen je uređaj za mikrovalnu digestiju uzoraka (Anton Paar, Multiwave 3000, rotor 8XQ), gdje je uzorak $(0,5 \mathrm{~g})$ otapan u zatvorenom sustavu uz dodatak $10 \mathrm{ml}$ dušične kiseline pri 60 bar i $240{ }^{\circ} \mathrm{C}$.

Nakon otapanja uzorci su razrijeđeni dodatkom ultračiste vode.

Određivanje bora atomskom apsorpcijskom spektrometrijom s grafitnom tehnikom zahtijevalo je i dodatnu obradu grafitne kivete, odnosno tzv. oblaganje grafitne kivete. Oblaganje grafitne kivete provedeno je dodatkom cirkonijeva klorida radi sprječavanja stvaranja borova karbida reakcijom ugljika iz grafitne kivete i bora iz uzoraka nodularnog lijeva.

\section{Rezultati i rasprava}

Rezultati ispitivanja optičkom emisijskom spektrometrijom s induktivno spregnutom plazmom i optičkom emisijskom spektrometrijom s izravnim očitanjem prikazani su u tablici 1.

Tablica 1 - Koncentracija bora u uzorcima nodularnog lijeva

Table 1 - Concentration of boron in samples of ductile cast iron

\begin{tabular}{|c|c|c|c|}
\hline \multirow{2}{*}{$\begin{array}{l}\text { Uzorak } \\
\text { Sample }\end{array}$} & \multicolumn{3}{|c|}{$\begin{array}{l}\text { Koncentracija bora } / \mathrm{kg} \mathrm{m}^{-3} \\
\text { Boron concentration } / \mathrm{kg} \mathrm{m}^{-3}\end{array}$} \\
\hline & $\begin{array}{l}\text { Očekivana koncentracija } \\
\text { Expected concentration }\end{array}$ & ICP-OES & OES \\
\hline 1 & - & 0,003 & 0,002 \\
\hline 2 & 0,005 & 0,0042 & 0,006 \\
\hline 3 & 0,010 & 0,0076 & 0,009 \\
\hline 4 & 0,015 & 0,015 & 0,012 \\
\hline 5 & 0,020 & 0,018 & 0,017 \\
\hline 6 & 0,030 & 0,028 & 0,022 \\
\hline 7 & 0,040 & 0,039 & 0,029 \\
\hline 8 & 0,050 & 0,053 & 0,039 \\
\hline 9 & 0,075 & 0,075 & 0,053 \\
\hline
\end{tabular}


Kolona koja prikazuje vrijednosti dobivene optičkom emisijskom spektrometrijom s induktivno spregnutom plazmom odnosi se na koncentracije bora dobivene analizom uzoraka koji su prevedeni u vodenu otopinu u uređaju za mikrovalnu digestiju. Otapanje uzoraka pokušalo se provesti na dva načina. Međutim otapanjem "klasičnim" putem (bez mikrovalne digestije) zaostao je veći dio neotopljenog uzorka, što ukazuje na slabu mogućnost otapanja na ovaj način. Pretpostavlja se da analizirani uzorci sadrže karbide koji su vrlo teško topljivi, odnosno ne mogu se otopiti na klasičan način. Osim toga otapanje je provedeno u otvorenom sustavu, što je vjerojatno prouzročilo i gubitak uzorka. Budući da je otapanje mikrovalnom digestijom provedeno uz povišeni tlak i u zatvorenom sustavu, dobivena je potpuno bistra otopina, koja je dalje analizirana na spomenutim uređajima (ICP-OES i AAS-GF).

Iz tablice 1 vidljivo je da su vrijednosti dobivene primjenom tih dvaju metoda vrlo slične. Nešto malo veće koncentracije bora dobivene su optičkom emisijskom spektrometrijom $\mathrm{s}$ induktivno spregnutom plazmom. Uz uvjet potpunog usvajanja bora u talini nodularnog lijeva, na osnovi udjela bora u leguri moguće je izračunati da bi očekivana koncentracija bora u uzorcima iznosila od 0,005 do 0,075 $\mathrm{kg} \mathrm{m}^{-3}$ (tablica 1). Vrijednosti dobivene optičkom emisijskom spektrometrijom s induktivno spregnutom plazmom nešto su više i bliže očekivanom udjelu bora u nodularnom lijevu od vrijednosti dobivenih optičkom emisijskom spektrometrijom s izravnim očitanjem. Razlog tome može biti razlika u homogenosti uzoraka. Naime, prilikom analize uzoraka optičkom emisijskom spektrometrijom s izravnim očitanjem iskra se usmjerava na točno određeno mjesto u uzorku. Uzorak na kojemu se provodi mjerenje u čvrstom je stanju i postoji mogućnost da nije potpuno homogen. Uzorci za analizu optičkom emisijskom spektrometrijom $\mathrm{s}$ induktivno spregnutom plazmom uzimaju se također iz Čvrstog uzorka piljenjem ili bušenjem na različitim mjestima, prolaze postupak miješanja (pri čemu se i homogeniziraju) i tek nakon toga otapaju, što u konačnici rezultira znatno homogenijim uzorcima. Vidljivo je da se određivanje bora optičkom emisijskom spektrometrijom s induktivno spregnutom plazmom može vrlo uspješno provesti unatoč prethodnom otapanju uzoraka. Može se zaključiti da se pažljivom pripremom uzoraka može eliminirati mogućnost gubitka pojedinih komponenti uzorka, što također utječe na točnost analize.

Iz dobivenih rezultata može se zaključiti da se optička emisijska spektrometrija s izravnim očitanjem može primijeniti za rutinsku, pogonsku analizu. Međutim, ako se zahtijeva vrlo točna analiza te posebno ako se radi o vrlo niskim koncentracija pojedinih elemenata u uzorcima, optička emisijska spektrometriju s izravnim očitanjem nije pogodna metoda. Donja granica detekcije ove vrste uređaja obično je nešto viša u odnosu na optičku emisijsku spektrometriju s induktivno spregnutom plazmom. Pored toga, optička emisijska spektrometrija s izravnim očitanjem nije pogodna za određivanje pojedinih rijetkih elemenata.

Rezultati analize dobiveni atomskom apsorpcijskom spektrometrijom s grafitnom tehnikom nisu prikazani zbog toga što mjerenje nije bilo moguće provesti. Već prilikom izrade baždarne krivulje nije bilo moguće dobiti odgovarajuće vrijednosti. Razlog za to treba tražiti u činjenici da je bor element koji ima visoku sklonost k stvaranju karbida. U ovom je radu primijenjena atomska apsorpcijska spektrometrija s grafitnom tehnikom zbog niže granice detekcije u odnosu na ostale tehnike atomske apsorpcijske spektrometrije. Međutim u toj se tehnici pri radu upotrebljava grafitna kiveta koja vrlo često reagira s elementima koji imaju sposobnost tvorbe karbida. Prema literaturnim podatcima ${ }^{6}$ stvaranje karbida sprječava se prethodnim oblaganjem grafitne kivete odgovarajućim sredstvima poput cirkonijeva klorida. Takav postupak proveden je i u ovom istraživanju, međutim oblaganje grafitne kivete nije spriječilo stvaranje karbida.

\section{Zaključak}

- Optička emisijska spektrometrija s induktivno spregnutom plazmom kao i optička emisijska spektrometrija s izravnim očitanjem mogu se primjenjivati za određivanje bora u metalurškim uzorcima.

- Optička emisijska spektrometrija s induktivno spregnutom plazmom točnija je metoda i posebno je pogodna za vrlo niske koncentracije elemenata, dok je optička emisijska spektrometrija s izravnim očitanjem brža i jednostavnija za primjenu.

- Na rezultate analize optičkom emisijskom spektrometrijom s induktivno spregnutom plazmom znatno utječe postupak pripreme/otapanja uzoraka, pri čemu se priprema uzoraka u uređaju za mikrovalnu digestiju pokazala povoljnijom.

- Atomska apsorpcijska spektrometrija s grafitnom kivetom ne može se primijeniti za određivanje bora budući da dolazi do tvorbe karbida reakcijom grafitne kivete s borom iz uzoraka.

- Oblaganje grafitne kivete cirkonijevim kloridom nije se pokazalo uspješnim u smislu sprječavanja tvorbe karbida.

\section{Popis simbola i kratica}

\section{List of symbols and abbreviations}
AAS-GF - atomska apsorpcijska spektrometrija s grafitnom tehnikom
- graphite furnace atomic absorption spectrometry
ICP-OES - optička emisijska spektrometrija s induktivno spregnutom plazmom
- inductively coupled plasma optical emission spectrometry
OES - optička emisijska spektrometrija s izravnim očitanjem - direct reading optical emission spectrometry 


\section{Literatura \\ References}

1. D. A. Skoog, J. L. Leary, Principles of Instrumental Analysis, Harcourt Brace \& Company, Florida, 1992.

2. S. Mendez, D. Lopez, I. Asenjo, P. Larranaga, J. Lacaze, Improved analytical method for chemical analysis of cast irons. Application to castings with chunky graphite, ISIJ International 51 (2) (2010) 242-249, doi: http://dx.doi.org/10.2355/isijinternational.51.242.
3. M. Tomljanović, Instrumentalne kemijske metode, U. G. Hijatus, Zenica, 2000.

4. R. L. Naro, J. F. Wallace, Y. Zhu, Elimination and Neutralization of Boron in Ductile Irons, URL: http://www.ductile.org/ researchpdfs/proj39.pdf (20. 6. 2015.).

5. W. Menk, S. Prukner, L. Kniewallner, Die Werstofffamilie SiboDur mit neuen Perspektiven für Gusseisen mit Kugelgraphit, Giesserei 98 (12) (2007) 30-35.

6. B. Welz, M. Sperling, Atomic Absorption Spectrometry, Wiley-VCH, Weinheim, 1999.

\title{
EXTENDED ABSTRACT
}

\author{
Application of Spectrometric Methods \\ in the Analysis of Metallurgical Samples \\ Anita Štrkalj* and Zoran Glavaš
}

Instrumental methods of analysis are indispensable in scientific research. They are also being used increasingly in practice to quickly obtain results and better accuracy. Spectrometric methods of analysis have been used for many years in the metallurgical practice. Direct reading optical emission spectrometry is the most commonly used method. However, concentrations of certain alloy in elements in modern metallic materials are very low, often below the limit of detection of the direct reading optical emission spectrometer.

In this article, the concentration of boron in ductile iron was determined by direct reading optical emission spectrometry (OES), the inductively coupled plasma optical emission spectrometry (ICP-OES), and graphite furnace atomic absorption spectrometry (AAS-GF). The obtained results showed that the direct reading optical emission spectrometry (OES) and inductively coupled plasma optical emission spectrometry (ICP-OES) were suitable methods for the determination of boron in the analyzed samples (Table 1). If very accurate analysis is required, especially in the case of very low concentrations, the more suitable method is inductively coupled plasma optical emission spectrometry provided that the samples are properly prepared. Graphite furnace atomic absorption spectrometry is not suitable for the determination of boron in samples of this type. During the analysis, additional attention was paid to the elimination of the negative impact of the graphite cuvette on the result of the analysis.

In this article it was also studied the influence of the process of dissolution of the samples on the obtained results. The results showed that careful preparation of samples in a closed system contributes to a more accurate result of analysis.

\section{Keywords}

Graphite furnace atomic absorption spectrometry (AAS-GF), inductively coupled plasma optical emission spectrometry (ICP-OES), direct reading optical emission spectrometry (OES), boron, metallurgical samples

University of Zagreb Faculty of Metallurgy

Aleja narodnih heroja 3, 44103 Sisak, Croatia
Original scientific paper Received June 29, 2015 Accepted September 2, 2015 